\title{
Пассивные оптические сети в сетях SmartGridPlus
}

\author{
Рин.Ш. Мисбахов ${ }^{1}$, И.Н. Лизунов ${ }^{1}$, Н.В. Васев ${ }^{1}$, \\ О.Г. Морозов ${ }^{2}$, И.И. Нуреев ${ }^{2}$, Рус.Ш. Мисбахов ${ }^{3}$ \\ ${ }^{1}$ Казанский государственный энергетический университет \\ ${ }^{2}$ Казанский национальный исследовательский технический университет им. А.Н. Туполева-КАИ \\ ${ }^{3} \mathrm{OAO}$ «ТатАИСнефть» \\ "E-mail:zerdex@bk.ru
}

DOI:10.31868/RFL2018.135-136

Современные микропроцессорные реле - это не только устройства, которые защищают электрогенерирующее оборудование разного класса напряжения, но также имеют возможность выполнять функции SCADA-систем, систем мониторинга и управления релейной защитой и аварийной автоматизацией. Эти функции реализованы при сканировании микропроцессорных реле по выбранным каналам связи систем сбора и передачи информации (IATS). Перспектива развития концепции «Цифровая подстанция» определяет необходимость развертывания единого межпланетного IATS для систем релейной защиты и автоматизации, SCADA и других систем автоматизации в соответствии с IEC 61850 (рис. 1), а по концепции SmartGridPlus и по волоконно-оптическим сетям от волоконно-оптических датчиков.

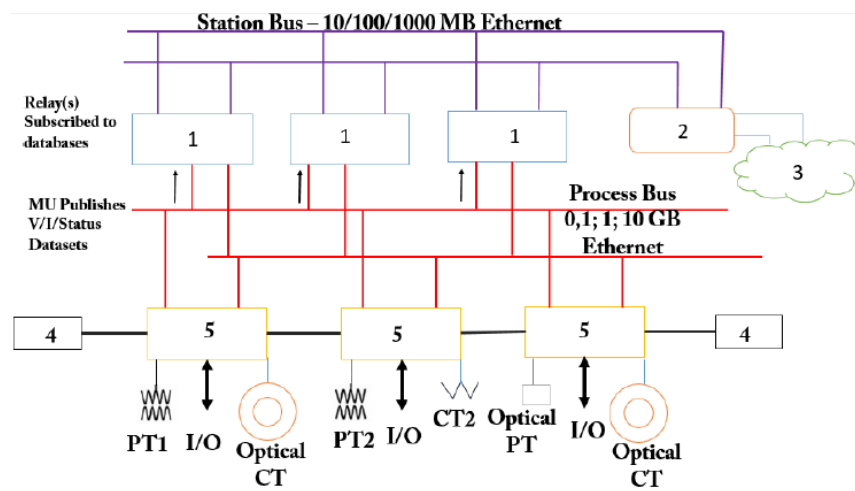

Рис.1. Модель электрической подстанции в соответствии с рекомендациями МЭК61850 и концепции SmartGridPlus: 1 - реле; 2 - узел доступа; 3 - сеть; 4 синхрошина; 5 - КРУ; РТ - трансформатор мощности; СТ - трансформатор тока; ОСТ/ОРТ - оптический трансформатор тока и мощности; сверху показана объектовая шина Ethernet

На фоне роста числа функций, выполняемых микропроцессорными реле, на оборудование и каналы связи возлагаются все более высокие требования к надежности, эффективности производства, избыточности, а также электромагнитной совместимости, включая создание сетей подстанций с нулевой потерей данных пакетов. Несмотря на очевидные преимущества, для организации сети, основанной на оптических каналах связи, необходимо иметь сложное активное коммуникационное оборудование - оптические коммутаторы, стоимость которых в несколько раз выше, чем у их обычных аналогов, и теперь этот факт ограничивает широкое использование оптических решений, повышая надежность электроснабжения и управления энергообъектами в целом.

В настоящее время благодаря созданию и широкому распространению в телекоммуникационной сфере более дешевых решений, основанных на технологиях XPON (ПОС), построение сетей со волоконно-оптическими линиями связи, становятся относительно доступными. В частности, одним из наиболее успешных в этой области является стандартный GPON (Gigabit PON). Ключевыми особенностями GPON являются использование только одного приемопередатчика (оптического линейного терминала) для приема и передачи информации во множество приемных устройств.

Более того, в отличие от традиционных сетей, основанных на оптическом волокне, нет необходимости устанавливать активные устройства в сетевых узлах; 
вместо этого линии ответвлений производятся от основного кабеля, используя оптические разветвители, и поэтому сетевая топология является «деревом с пассивными узлами».

Ключевыми аспектами этой технологии, позволяющей ее реализовать на объектах электроэнергетики, являются:

- возможность установки модульных компактных приемопередатчиков в формате стандарта SFP (Small Form-factor Pluggable) в микропроцессорных реле или в контроллерах отсека SCADA для организации каналов связи IATS;

- компактность сплиттера позволяет размещать их в труднодоступных местах, в пределах модулей релейной защиты и автоматизации в ячейках среднего напряжения;

- независимый формат передаваемых единиц;

- маршрутизация пакетов реализована в устройствах приема, благодаря механизму управления данными GTC;

- стандарт GPON поддерживает следующие скорости: поток вниз (от OLT, downstream) передается со скоростью 1,25-2,5 Гбод, поток вверх (с ONT, upstream) передается со скоростью от 0,155 до 1,25 ГБ.

Рассмотрим результаты исследования качества сетевого сигнала GPON 2,5 ГБод. Для исследования использовалась имитационная модель программного обеспечения OptiSystem, включающая генератор случайных чисел, генератор импульсов NRZ, модулятор Маха-Цендера, непрерывный источник лазерного излучения, фильтр нижних частот, BER-анализатор, оптический бесселевый фильтр, 3R регенератор (рис. 2).

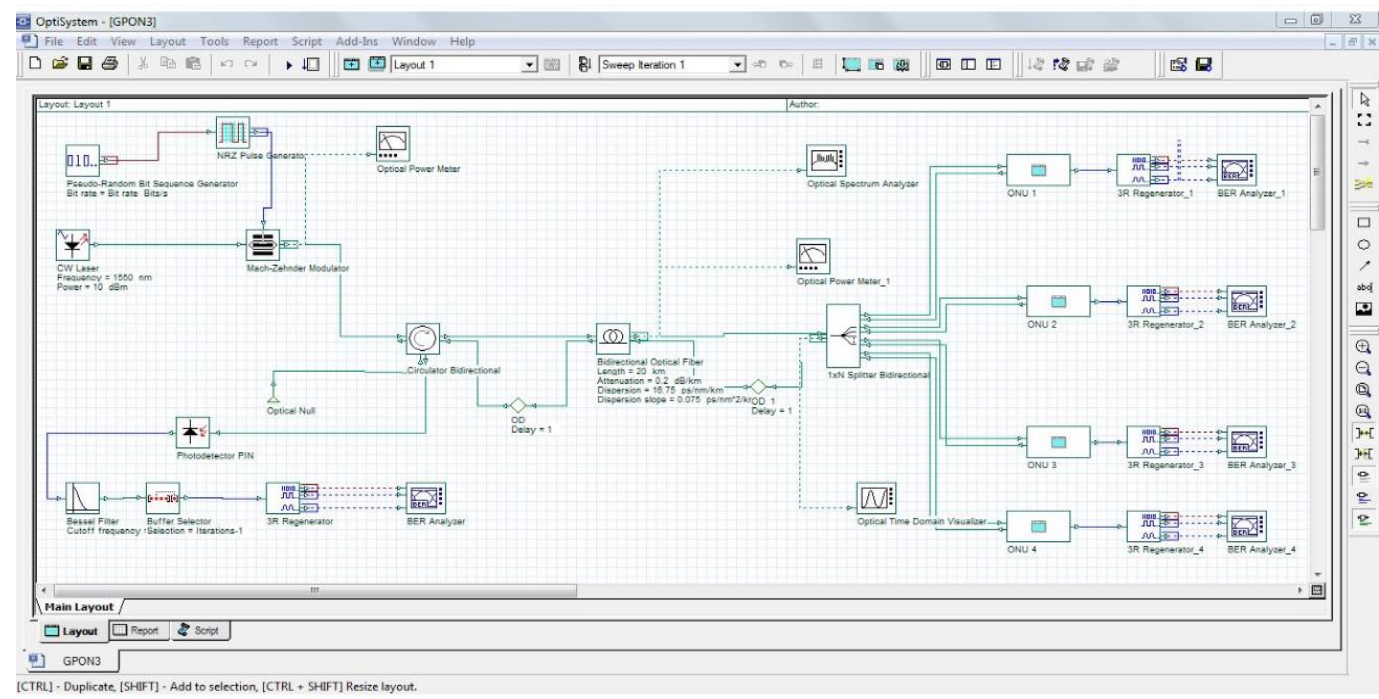

Рис. 2. Модель сети GPON в OptiSystem

Согласно результатам моделирования сетей GPON, полученным в исследовании (с одним OLT и множеством ONT) на длине волны 1550 нм на длине участка оптического волокна 20 км, параметры BER были получены для ONT OLT $1,29 \cdot 10^{12}$ и $4 \cdot 10^{-8}$ соответственно. Кроме того, в докладе обсуждаются глаздиаграммы, демонстрирующие низкий уровень шума и джиттера.

Применение технологии GPON для создания цифровой подстанции SmartGridPlus в централизованных системах управления, защиты и сигнализации на энергообъектах класса среднего напряжения могут обеспечить высокую надежность и высокоскоростную передачу данных. 